\title{
OBJETIVOS DO DESENVOLVIMENTO SUSTENTÁVEL E LAUDATO SI NA AGENDA SÓCIOECONÔMICA E AMBIENTAL DA ATUALIDADE
}

\section{SUSTAINABLE DEVELOPMENT GOALS AND LAUDATO SI IN THE CURRENT SOCIO-ECONOMIC AND ENVIRONMENTAL AGENDA}

\author{
Copyright @ 2021 Fipecafi. Todos os direitos reservados.
}

Recebido em: 29/03/2021. Modificações requeridas em: 25/08/2021. Aceito em: 14/01/2022

DOI: https://doi.org/10.53826/2763-7069.v2n1.2021.id29

Caio Odack Silva

Universidade de São Paulo (FEA/USP) - São Paulo (Brasil) caio.oldack.silva@gmail.com

José Roberto Kassai

Universidade de São Paulo (FEA/USP) - São Paulo (Brasil) jrkassai@usp.br

\section{RESUMO}

O objetivo deste estudo foi identificar as contribuições singulares e as relações entre as agendas socioeconômica e ambiental da Organização das Nações Unidas (ONU) e da Carta Encíclica Laudato Si do Vaticano, se complementando para a realização dos objetivos a que se propõem. Trata-se de uma pesquisa qualitativa de natureza exploratória e descritiva e baseia-se na suposição de que, embora elas tratem basicamente dos mesmos temas - como extrema pobreza, agricultura e alimentação, energia e água, saneamento, dentre outros - , uma pode complementar a outra com aspectos singulares. Esta investigação se justifica pela relevância do tema e pelas contribuições dessas agendas elaboradas por duas grandes entidades. Os resultados obtidos revelam o entendimento de que as duas agendas mundiais apresentam importantes singularidades em suas abordagens, mas que, consideradas as diferenças de posicionamento político e moral que os documentos possuem perante a sociedade, resulta-se a existência de uma concordância em relação à integralidade dos temas tratados. Por fim, conclui-se que enquanto a agenda da ONU tem por objetivo promover mudanças externas para a construção de um mundo melhor para as próximas gerações, a agenda do Vaticano mostra que também é necessária a promoção de mudanças internas dos indivíduos, com base em novos conceitos de felicidade que atinjam e preencham os corações e sentimentos.

PALAVRAS-CHAVE: Sustentabilidade. 17 ODS. Encíclica Laudato Si.

\section{ABSTRACT}

The aim of this study was to identify the unique contributions and relationships that the socioeconomic and environmental agendas of the United Nations (UN) and the Vatican's Encyclical Laudato Si have, complementing each other for their proposed objectives achievement. It is a qualitative research of exploratory and descriptive nature which is based on the assumption that, although they basically deal with the same themes - such as extreme poverty, agriculture and food, energy and water, sanitation, among others - one can complement the other with unique aspects. This investigation is justified by the relevance of the theme and the contributions of these 


\section{OBJETIVOS DO DESENVOLVIMENTO SUSTENTÁVEL E LAUDATO SI NA AGENDA SÓCIOECONÔMICA E AMBIENTAL DA ATUALIDADE}

agendas prepared by two important entities. The results reveal the understanding that the two world agendas have important singularities in their approaches, but considering the differences that the documents have in political and moral positioning in society, there is an agreement in relation to the completeness of their covered topics. Finally, it is concluded that while the UN agenda aims to promote external changes to build a better world for the next generations, the Vatican agenda shows that it is also necessary to promote internal changes in individuals, based on new concepts of happiness that reach and fill hearts and feelings.

KEYWORDS: Sustainability. 17 ODS. Encyclical Laudato Si.

\section{INTRODUÇÃO}

Superpopulação, megacidades, hiperconsumo. A busca incessante pelo conforto, pela erradicação das inseguranças, das incertezas do sobreviver contemporâneo. A criação de necessidades, a oferta de oportunidades que em seu todo se retroalimentam. Vivemos em um mundo que se estrutura sobre bases financeiras, sobre o consumo, em que o crescimento aliado à lucratividade material é protagonista na concepção dos valores sociais. Um sistema acreditado como sustentável que, porém, em sua complexidade antrópica, se descuida de seus alicerces inegáveis, de sua genealogia fundamental. Enfrentamos hoje o grande inconveniente denominado aquecimento global. Causa e efeito de diversas atividades e comportamentos humanos, o assunto cresce cada vez mais em importância por colocar em jogo não apenas a sustentabilidade econômica, mas também a perpetuidade da vida em nosso planeta. Dos primórdios da industrialização, das descobertas revolucionárias na ciência, das novas formas de se fazer e pensar o público e o privado.

O mundo em que vivemos passou por mudanças drásticas nos últimos dois séculos, e o cenário atual é representativo dos sintomas de um desenvolvimento acelerado. O século 21 apresenta uma população absoluta de mais de 7 bilhões de seres humanos. Uma população que anualmente bate recordes de produção, de consumo, mas que se distancia a passos largos do seu estado mais natural de existência. Isso se mostra claro pela análise da contrapartida gerada pelo desenvolvimento econômico-informacional. Recursos naturais nunca foram tão demandados, os graus de desmatamento e poluição já aparentam ser quase irreversíveis à medida que nos "desenvolvemos", e os problemas sociais, como a desigualdade e a miséria, ainda rugem em meio às ilhas de luxo do sistema financeiro. E o indivíduo desenvolvido, em sua unidade, perde seu protagonismo para o material, mudando a forma como ele compreende o mundo e se relaciona com as pessoas. O contexto atual é repleto de desequilíbrio, de problemas originários da forma como o desenvolvimento da humanidade foi estruturado, que se relacionam à distribuição do poder, e aos interesses e influência de quem o detêm na vida coletiva.

Os problemas estão estabelecidos, claros, e os caminhos para uma possível solução para eles já começaram a ser traçados. Em busca de um mundo melhor e mais igualitário, com iniciativa da ONU, foi divulgado durante a Cúpula das Nações Unidas sobre o Desenvolvimento Sustentável, em setembro de 2015, os 17 Objetivos do Desenvolvimento Sustentável. São 17 objetivos e 169 metas a serem alcançadas até 2030, e que abrangem uma grande complexidade de temas, problematizando desde a erradicação da pobreza, educação, até as mudanças climáticas e padrões sustentáveis de produção e consumo.

Esforços com esse mesmo fim não são novidade na história recente, no 
entanto, o desenvolvimento sustentável não poderia ser mais bem traduzido em sua interdisciplinaridade como nos 17 ODS, que integram a chamada "Agenda 2030". Sucessores dos Objetivos do Desenvolvimento do Milênio (ODM), com vigência de 2000 a 2015, os 17 ODS fundamentaram o interesse e o desejo social de um futuro melhor. Vem se tornando cada vez mais clara a interdependência entre a vida humana e o meio no qual ela se estabelece, a ponto de ser hoje inquestionável essa relação. Muitas são as partes interessadas, e com uma abordagem que prioriza essa interrelação, foi publicada pelo Vaticano a Carta Encíclica Laudato Si. Nela, o objetivo de alcançar um mudo melhor e menos desigual se vê traduzido na compreensão científica, mas sobretudo religiosa e moral, de seu autor, Papa Francisco. Laudato Si, assim denominada a encíclica em questão, que se caracteriza por sua interdisciplinaridade ao encarar a axiomática realidade atual, sendo destaque ao elevar a importância do indivíduo, de seus hábitos e valores, e do coletivo como base para solução dos problemas econômicos, sociais e ambientais.

Por meio de uma pesquisa qualitativa de natureza exploratória e descritiva, este estudo propôs a investigação dessas que são duas das principais agendas ambientais da atualidade. Ambas se dedicam a temas de grande semelhança e são marcadas pela grande interdisciplinaridade. Extrema pobreza, saúde, agricultura e alimentação, energia e água, mudanças climáticas, são alguns exemplos. Ponderando a conexão entre elas, a questão que fundamentou a pesquisa foi: considerado o cenário socioambiental da atualidade, de que forma as duas principais agendas mundiais se relacionam e se complementam na realização dos objetivos a que se propõem? A investigação proposta teve fins na análise dessas agendas e na identificação de aspectos singulares que as diferenciam e as complementam. O estudo obteve como resultado o entendimento de que as duas agendas mundiais apresentam importantes singularidades de abordagem, mas que consideradas as diferenças de posicionamento político e moral perante a sociedade que os documentos possuem, resulta-se a existência de uma concordância em relação à integralidade dos temas tratados. Por fim, conclui-se que enquanto a agenda da ONU tem por objetivo promover mudanças externas para a construção de um mundo melhor para as próximas gerações, a agenda do Vaticano mostra que também é necessária a promoção de mudanças internas dos indivíduos, com base em novos conceitos de felicidade que atinjam e preencham os corações e sentimentos.

\section{FUNDAMENTAÇÃO DAS DUAS AGENDAS}

\subsection{Os 17 Objetivos do Desenvolvimento Sustentável (ODS)}

Dos dias 25 a 27 de setembro de 2015, estiveram reunidos, em Nova York, na sede das Nações Unidas, Chefes de Estado e de Governo e Altos Representantes para elaboração daquela que viria a ser denominada Agenda 2030. Partindo de um conceito baseado na definição de objetivos e metas universais, abrangentes, de longo alcance, e voltados para as pessoas, a agenda idealiza a paz universal com mais liberdade, expondo um plano de ação que prioriza as pessoas, o planeta e a prosperidade. Como maior desafio a ser enfrentado em nível global, a pobreza extrema foi considerada um problema de solução indispensável para a experiência de um desenvolvimento sustentável. Outro fator imprescindível é a existência de uma intensa colaboração internacional, que promova um eficiente fluxo econômico, social e informacional entre as nações participantes, sobretudo ao se pensar nos diferentes graus de desenvolvimento e níveis de desigualdade que os países apresentam. 
Segundo os agentes participantes, a urgência dessa jornada coletiva demanda por sustentabilidade e resiliência, sendo a agenda fundamental para a libertação da raça humana quanto à "tirania" da pobreza e da privação, e à preservação e proteção do nosso planeta.

São 169 metas que compõem os 17 Objetivos de Desenvolvimento Sustentável (17 ODS) anunciados, definindo o que se mostra ser uma agenda universal de grande abrangência e ambição. Com vigência de 2016 até 2030, os 17 ODS sucederam e podem ser considerados herança dos Objetivos de Desenvolvimento do Milênio (ODM), que tiveram vigência de 2000 a 2015. Apesar de os ODM terem promovido um progresso significativo ao longo de sua execução, se concluiu que o progresso atingido foi desigual. Além de alguns dos objetivos traçados ainda estarem longe de serem alcançados, países menos desenvolvidos, sobretudo os africanos, países em desenvolvimento sem litoral e os pequenos Estados insulares em desenvolvimento, tiveram um progresso muito inferior. Nesse sentido, a Agenda 2030 se mostra comprometida com o cumprimento de todos os Objetivos de Desenvolvimento do Milênio, mas se propõe a ir muito além, em sua abrangência e meios de implementação. O âmago de suas metas gira em torno da erradicação da pobreza, promoção da saúde, educação e segurança alimentar e nutricional, além de novos objetivos econômicos, sociais e ambientais, que promovam sociedades mais pacíficas e inclusivas. Como afirmado pela Agenda 2030, ela tem como inspiração os Objetivos de Desenvolvimento do Milênio e se propõe cumprir com o que por eles não foi alcançado.

Se tratando dos novos objetivos e metas, os 17 ODS, eles levaram em conta uma abordagem voltada para diferentes áreas de ação, baseados nos princípios dos denominados "Cinco P's": pessoas, planeta, parcerias, paz e prosperidade, que podem ser assim detalhados:

- Pessoas: erradicar a pobreza e a fome de todas as maneiras e garantir a dignidade e igualdade.

- Planeta: proteger os recursos naturais e o clima de nosso planeta para as futuras gerações.

- Parcerias: Implementar a agenda por meio de uma parceria global sólida.

- Paz: promover sociedades pacíficas, justas e inclusivas.

- Prosperidade: garantir vidas prósperas e plenas, em harmonia com a natureza. (KASSAI; CARVALHO; KASSAI, 2019, p. 269).

Os 17 Objetivos de Desenvolvimento Sustentável entraram em vigor em $1^{\circ}$ de janeiro de 2016 e a dedicação à coletividade por meio, sobretudo, da cooperação internacional é fundamental para sua implementação, sendo essa cooperação fonte de enormes ganhos para todos os países em diferentes partes do mundo. O compromisso acordado entre os participantes é o da plena implementação dessa Agenda até 2030. Questões de altíssima relevância social, como tema da igualdade de gênero e o empoderamento das mulheres nunca estiveram tão presentes, promovendo uma intensificação na luta contra todas as formas de discriminação e violência contra as mulheres e meninas. A implementação das metas ao longo dos próximos quinze anos também levará em consideração a importância da soberania nacional dos países, nas suas diferentes realidades nacionais, capacidades e níveis de desenvolvimento, respeitando as políticas e prioridades nacionais. Tudo isso de modo a promover um crescimento econômico igualitário, inclusivo e sustentável, e que se dissocie da degradação ambiental.

\subsection{Encíclica do Papa Francisco - Laudato Si (2015)}


Em 2015 foi publicada pelo Vaticano a encíclica papal nํ2 298, que recebeu 0 título "Laudato Si, sobre o cuidado da casa comum". Apesar de recente, a Laudato Si já pode ser considerada uma encíclica histórica por se tratar da primeira vez em que um papa, Francisco, se posiciona formalmente a respeito da proteção e preservação do meio ambiente. A encíclica papal é uma comunicação escrita, um documento pontifício de abrangência universal, que se volta aos bispos e, sendo assim, aos fiéis de todo o mundo. Portanto, possui um importante papel na história, orientando fiéis, mas não somente a eles, dada a relevância da entidade Igreja Católica, que influencia em grande medida a concepção de valores morais e políticas públicas em diferentes nações. Aencíclica pode ser vista também como um importante símbolo do exercício da autoridade papal como o grande líder da instituição religiosa que representa.

O documento contém 246 parágrafos distribuídos em seis capítulos e foi elaborado pela Pontifícia Academia de Ciências do Vaticano, sob coordenação do Chanceler Dom Marcelo Sorondo. Inclui ganhadores do prêmio Nobel e especialistas, a exemplo do inglês Stephen Hawking (1942-2018) e do brasileiro Professor Virgílio Maurício Viana, um dos maiores especialistas em florestas amazônicas" (KASSAI; CARVALHO; KASSAI, 2019, p. 276).

O texto aborda temas muito abrangentes, elucidando diversas questões de cunho socioambiental e econômico, e fundamenta a sua essência ao determinar como vital a importância do indivíduo para o alcance de um mundo melhor. Não haverá, segundo o papa, mudanças sustentadas sem que exista o desenvolvimento de uma nova consciência e que ela seja perpetuada dentro do coletivo. À luz dessa nova consciência, Francisco estrutura o que denomina como ecologia integral, que ao englobar a vida, o humano, a economia, a sociedade, a cultura e o meio ambiente, expressa o valor da interdisciplinaridade que percorrerá todo seu pensamento. O meio ambiente é um bem coletivo, patrimônio da humanidade e responsabilidade de todos. A intervenção humana ideal deve se relacionar de forma a favorecer a natureza e, consequentemente, protegê-la. Os hábitos e costumes atualmente preconizados são devastadores com seu materialismo, tecnocracia e consumismo exagerado. Por meio da encíclica papal ํㅡ 298, o Papa Francisco fala do mundo e para o mundo, enaltecendo a interligação entre o ser humano e a natureza, trazendo à luz um novo conceito para a ecologia, evidenciando a existência de laços universais: o indivíduo, o seu próximo, o meio ambiente e o criador.

\section{PROCEDIMENTOS METODOLÓGICOS}

O estudo se deu por meio de uma pesquisa qualitativa de natureza exploratória e descritiva, dessas que são duas das principais agendas da atualidade. Ambas se dedicam a temas semelhantes e são marcadas pela sua interdisciplinaridade, que se mostra também ao propor soluções para os problemas identificados. No entanto, possuem abordagens distintas, ao tratarem de um mesmo tema, e se utilizam de concepções que variam pelos caminhos da objetividade e subjetividade.

Uma breve análise daquilo que representa o objetivo central das agendas permitiu a identificação de uma convergência entre a essência que ditou a construção de ambas. Integração, transformação, desenvolvimento e universalização, envolvendo as esferas social, econômica e ambiental. O presente estudo se propôs a segmentar, por meio dessas esferas, o grande complexo temático pelo qual cada agenda, da sua forma, se desenvolve.

Essa escolha de segmentação por três grandesáreas poderia vir a ser contestada, uma vez que o próprio Papa Francisco afirmou que "não há duas crises separadas: uma ambiental e outra social” (FRANCISCO, 2015, p. 108). E é considerável afirmar 


\section{OBJETIVOS DO DESENVOLVIMENTO SUSTENTÁVEL E LAUDATO SI NA AGENDA SÓCIOECONÔMICA E AMBIENTAL DA ATUALIDADE}

que a leitura, tanto da Agenda 2030 como da encíclica Laudato Si, seja conclusiva em evidenciar a grande interdisciplinaridade entre as temáticas, demonstrando que o desenvolvimento socioeconômico e o meio ambiente, definitivamente, não são mais assuntos entendidos como distintos. Não é com o intuito de negar essa interrelação que o estudo propôs a segmentação dos temas. Pelo contrário, essa dependência, que caracteriza o que se entende hoje como desenvolvimento sustentável, não deixou de ser evidenciada. Porém, devido à grandiosidade e complexidade dos assuntos tratados, facilitará a compreensão uma análise comparativa que organize as temáticas pelas esferas mencionadas: social, econômica e ambiental.

São 20 os principais temas abordados pelas agendas, os quais fundamentam a sua abordagem. No âmbito da esfera social, são temas principais: a erradicação da pobreza; a erradicação da fome; segurança alimentar; agricultura sustentável; saúde e bem-estar; educação; igualdade de gênero; água e saneamento; promoção de sociedades pacíficas e inclusivas; construção de instituições eficazes, responsáveis e inclusivas em todos os níveis; implementação e parcerias globais. Já no âmbito da esfera econômica, são abordados os temas: crescimento econômico sustentável; emprego; industrialização e infraestrutura; desigualdade dentro dos países e entre eles; cidades sustentáveis; padrões de produção e consumo. No âmbito da esfera ambiental, são temas: combate às mudanças climáticas e seus impactos; energia; conservação e uso sustentável dos oceanos; proteção, recuperação e promoção do uso sustentável dos ecossistemas terrestres.

A divisão/proporção dos âmbitos nas agendas pode ser representado pelo gráfico da Figura 1.

Figura 1: Porcentagem temática nas esferas social, econômica e ambiental

Agenda 2030 e Encíclica Laudato Si:

Porcentagem de temas por esfera (\%)

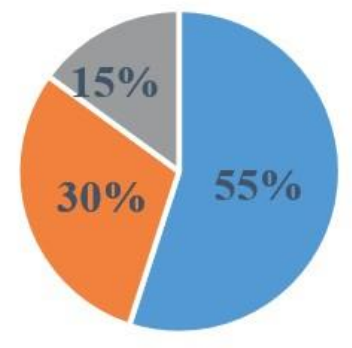

- Esfera social $=$ Esfera econômica " Esfera ambiental

Fonte: Elaborada pelos autores

O documento utilizado da Agenda 2030 para o estudo é de versão traduzida do inglês pelo Centro de Informação das Nações Unidas para o Brasil (UNIC Rio) e revisada pela Coordenadoria-Geral de Desenvolvimento Sustentável (CGDES) do Ministério das Relações Exteriores do Brasil. A edição última é datada de 11 de fevereiro de 2016. Trata-se de um documento formado por 55 páginas, nas quais são distribuídos um preâmbulo, seguido por 91 parágrafos que contemplam desde um capítulo introdutório, ao capítulo final de acompanhamento e revisão. Não incluso na contagem de parágrafos, está o capítulo que se volta exclusivamente à apresentação dos 17 Objetivos do Desenvolvimento Sustentável e suas 169 metas.

A Encíclica papal Laudato Si, de número 298 e de autoria do Papa Francisco, 
é um documento oficialmente disponibilizado pelo site do Vaticano, em 14 diferentes idiomas. O documento possui 192 páginas, nas quais estão distribuídos 6 capítulos compostos por um total de 246 parágrafos.

Sendo estabelecidas as segmentações temáticas, o estudo se desenvolveu na análise das abordagens utilizadas por ambas as agendas por esfera (social, econômica e ambiental) e respectivos subtemas. Como resultado da análise, o estudo apresentou um percentual de concordância em relação aos temas tratados e as abordagens utilizadas pelas duas agendas mundiais. Foram também apresentadas as principais singularidades identificadas entre os dois documentos. Por fim, tornou- se possível a conclusão efetiva do estudo, de que por meio de abordagens que se contrastam no modo como percebem e propõem soluções para a problemática global, as duas agendas se complementam.

\section{RESULTADOS E DISCUSSÕES}

\subsection{Resultado da análise das abordagens por segmentação}

\subsubsection{A esfera social}

A pobreza, considerada em todas suas formas, é tratada como tema fundamental nas duas agendas. Tida como o maior desafio global, a erradicação da pobreza é requisito indispensável para o desenvolvimento sustentável. O ODS 1 contempla justamente as metas propostas para que, até 2030 , a pobreza acabe em todas as suas formas, em todos os lugares, da erradicação da extrema pobreza, reduzindo à metade o número de pessoas que nela vivem, à implementação de medidas e sistemas de proteção social. Para tanto, é evidenciada a importância da garantia de igualdade de direitos e a acessibilidade aos recursos econômicos e tecnológicos. A cooperação internacional também se mostra fundamental, por meio do apoio aos países em desenvolvimento ou subdesenvolvidos. Essa é a postura da Agenda 2030, que também faz menção à vulnerabilidade dos mais pobres, à desastres econômicos, sociais e sobretudo, ambientais.

A encíclica Laudato Si não é diferente ao enfatizar a relevância dessa problemática. Como anteriormente citado, a crise que vivemos é de caráter social e ambiental, e é sustentado pelo Papa que, não há solução sem uma abordagem integral, que leve em conta o combate à pobreza, a devolução da dignidade aos excluídos e o cuidado com a natureza. No entanto, seguindo uma postura mais crítica e conclusiva a respeito das relações socioeconômicas, o Papa discorre sobre a ganância, o acúmulo excessivo de poder econômico, que apenas negligência a condição dos mais fracos. $O$ desenvolver da encíclica tratará dos temas cooperação internacional e acessibilidade, mas o que se destaca é sua singularidade ao criticar comportamentos do sistema de poder econômico vigente.

Ligado à pobreza, ambas agendas se posicionam a respeito da fome. A Agenda 2030, mais precisamente no ODS 2, define como meta a erradicação da fome e a segurança alimentar. Assim sendo, também objetiva acabar com a desnutrição em suas diversas formas. Nesse contexto, a agricultura sustentável tem um papel essencial. A agenda se compromete em dobrar a produtividade agrícola e a renda dos pequenos produtores, garantir maior investimento em tecnologia, infraestrutura, promoção da biodiversidade, cooperação internacional e equilíbrio econômico. Assim, a Agenda 2030 se compromete a lutar contra a fome, alinhando-se aos compromissos com a 
natureza e com sociedade. A encíclica papal traz em si uma perspectiva semelhante ao lidar com o tema. Ao citar a crença cega no crescimento do mercado como solução universal, o Papa critica a postura com que a economia atual lida com os problemas do mundo. Conclui que o mercado por si mesmo não é garantia de desenvolvimento e inclusão social, o mesmo sendo válido para a tecnologia. Francisco, então, ressalta a importância das instituições econômicas e programas sociais, que permitam o acesso aos recursos básicos. A atenção aos pequenos produtores é também um ponto de convergência entre as agendas. O Papa, no entanto, vai além, criticando a concentração de terras, que tem consequência direta no desaparecimento da agricultura familiar. Nesse contexto, a encíclica ressalta a importância do debate científico e social, que permita o acesso e participação de todos afetados, além do investimento em infraestrutura rural, que é considerado essencial.

São objetivos da Agenda 2030 assegurar saúde e promover o bem-estar para todos. Conforme expresso no ODS 3, a agenda se compromete com a redução da taxa de mortalidade materna, de crianças e recém-nascidos, com o fim das epidemias e propõe a prevenção como caminho para a promoção da saúde física, mental e do bem-estar. É também compromisso o acesso universal à saúde sexual e reprodutiva. A encíclica papal é congruente quanto ao tema, mas dá maior destaque ao impacto na saúde humana, das mudanças climáticas, ambientais e da poluição, tema que figura a quarta meta do ODS 12. O valor medicinal das plantas, parte de uma biodiversidade ameaçada, é também enfatizado, sendo, por fim, complementar aos objetivos da agenda da ONU.

Mais um tema de grande relevância é a água e o saneamento. Objeto do ODS 6, a Agenda 2030 se compromete com a disponibilidade e gestão sustentável da água e saneamento, para todos. São propostas melhorias na qualidade da água, redução da poluição e melhor eficiência no uso. Tudo isso por meio de uma gestão integrada, cooperação internacional e local, sobretudo quanto aos países em desenvolvimento. A encíclica, por outro lado, aborda a questão da água de maneira mais crítica às origens do problema. O documento aponta para a existência de uma grave dívida social para com os pobres sem acesso à água potável, por se tratar um direito humano essencial, fundamental e universal. Com o uso desregrado, passa-se a existir muitas regiões onde há um excesso de consumo que gera um desequilíbrio estrutural. Negar o direito à água potável aos pobres é, segundo o Papa, negar o direito à vida. Converge-se, então, a reflexão crítica e profunda de Francisco, à realização das metas da Agenda 2030.

O tema da educação está presente e é crucial para ambas as agendas. Objetivase o acesso universal à educação inclusiva e de qualidade, para o qual o ODS 4 apresenta metas que contemplam o ensino de primeira infância, o primário, o secundário e o técnico, sendo foco o investimento em infraestrutura, maior especialização dos alunos para o mercado de trabalho e políticas de inclusão dos mais vulneráveis. A encíclica, por outro lado, complementa o objetivo ao priorizar a relação da educação com as diversas mudanças ideológicas e comportamentais que ela propõe. Em um contexto de altíssimo individualismo, consumo e bem-estar, Francisco afirma ser um desafio da educação o desenvolvimento de hábitos e pensamentos em defesa do meio ambiente. Assim, ressalta a importância dos educadores na promoção de uma ética e equilíbrio ecológico. Vale dizer que, como no ODS 13, a Agenda 2030 menciona a importância da educação ambiental, mas é na Laudato Si que o tema ganha destaque.

Da promoção de sociedades pacíficas e inclusivas, à construção de instituições eficazes e implementação de parcerias, são muitos os temas em que as convergências 
e singularidades continuam, como é o caso da redução da desigualdade de gênero, tema que recebe menor ênfase na encíclica papal, em contraste com o ganho de notoriedade dado pela Agenda 2030, ODS 5.

O documento do Vaticano enaltece o papel da diplomacia e das políticas públicas, no que se lê que "precisamos duma política que pense com visão ampla e leve por diante uma reformulação integral, abrangendo num diálogo interdisciplinar os vários aspectos da crise" (FRANCISCO, 2015, p. 150). Nesse sentido, a temática da corrupção entra em cena. É uma meta do ODS 16 a redução da corrupção em todas suas formas, porém, é na encíclica papal que o tema recebe maior atenção. A política cresce em importância, e se torna ponto de crítica a ineficiência das leis, que afeta 0 Estado e as instituições sociais. Assim sendo, o Papa destaca a importância de uma população participativa e com capacidade de cobrança, pela qual, por meio da cooperação local, seja possível o controle civil do poder político e, consequentemente, o combate aos danos ambientais.

\subsubsection{A esfera econômica}

Assegurar padrões de produção e de consumo sustentáveis. É assim intitulado o ODS 12, que aborda metas para o desperdício, redução de resíduos, reciclagem, e conscientização social. A agenda tem como um de seus diferenciais o incentivo às empresas à adoção de práticas sustentáveis e relatórios de sustentabilidade. A temática tem caráter essencial na constituição da encíclica Laudato Si. Por meio da vinculação dos padrões de produção e consumo à precariedade socioambiental do mundo, o Papa formula uma crítica intensa à lógica econômica da maximização do lucro. São diversas as decisões e atitudes que se cegam na busca única da lucratividade financeira, negligenciando irresponsavelmente todos os custos sociais e ambientais que acarretam. Um comportamento só seria, então, considerado ético se assumisse responsabilidade integral e transparente de seus custos, não sendo eles suportados por outras populações nem pelas gerações futuras. Assim, o Papa é complementar à causa, por sua abordagem que enaltece o papel da espiritualidade e do ensinamento bíblico sobre a convicção de que "quanto menos, tanto mais", apontando para as distrações que o consumo traz ao coração, que nos impedem de valorizar as pequenas coisa e momentos.

Se relaciona a esse contexto o tema do crescimento econômico. Parte da Agenda 2030, o ODS 8 tem como metas a promoção de um crescimento econômico sustentado, inclusivo, que gere empregos decentes, promovendo o empreendedorismo e a criatividade, empregando jovens, reduzindo o desemprego e dando fim ao trabalho infantil e forçado. O texto é ambicioso e converge com a abordagem da encíclica Laudato Si. O documento de Francisco funciona como um reforço à necessidade da defesa do trabalho, que é considerado parte da concepção divina do ser humano. Se interlaçando à temática da produção e consumo, a encíclica fala de uma luta contra a desfiguração do sentido do trabalho, que se vê ameaçado pelo imediatismo econômico, contrário ao ritmo orgânico da natureza. O documento, então, destaca a existência de novas modalidades de crescimento, que reduzam o ritmo de produção e consumo, mas que promovam, sim, rentabilidade por meio da diversificação econômica e do equilíbrio ecológico. É também objeto de crítica do Papa a desigualdade dentro e entre os países, assunto do ODS 10, em que ambas as agendas convergem, ao demonstrar a responsabilidade dos países desenvolvidos perante as dificuldades das nações mais pobres, historicamente exploradas dentro de uma lógica de dominância de países do Norte industrializado sobre o Sul. Nesse sentido, as agendas apontam 
para prioridades diferentes e responsabilidades diversificadas quanto às mudanças climáticas.

Último grande tema da segmentação econômica criada, as cidades ganham um papel inédito e fundamental nas duas agendas. Tema que nos antigos ODM não havia recebido devida atenção, é abordado pelo ODS 11, que vincula urbanização inclusiva, por meio do acesso universal à moradia e transporte de qualidade, aos desafios ambientais do mundo. O documento do Papa Francisco não é diferente, porém, seu lado crítico é mais uma vez destaque. O documento lida com o conceito do bem comum, como um "conjunto das condições da vida social que permitem, tanto aos grupos como a cada membro, alcançar mais plena e facilmente a própria perfeição" (FRANCISCO, 2015, p. 121). A análise de Francisco, sobre o conceito de bem comum, se estende ao longo da encíclia e toca em pontos que atingem a subjetividade humana, como se constata no trecho a seguir.

Nota-se hoje, por exemplo, o crescimento desmedido e descontrolado de muitas cidades que se tornaram pouco saudáveis para viver, devido não só à poluição proveniente de emissões tóxicas, mas também ao caos urbano, aos problemas de transporte e à poluição visual e acústica (FRANCISCO, 2015, p. 35)

O bem comum estaria então comprometido. Com efeito, a encíclica evidencia ser importante que as diferentes partes de uma cidade estejam integradas, de modo que não se perca a visão do conjunto por parte dos habitantes. A intervenção humana na paisagem urbana ou rural pode ser definitiva na forma como o indivíduo vivencia e significa esse meio e, portanto, deve ser controlada de forma a priorizar o espaço comum. Apresentada na primeira das metas do ODS 11 e no corpo da encíclica, a urbanização das favelas é um exemplo dessa convergência entre as agendas na compreensão de que a integração da cidade e a criação de uma harmonia visual e social são fundamentais, sendo novos fatores de progresso.

\subsubsection{A esfera ambiental}

"A terra, nossa casa, parece transformar-se cada vez mais num imenso depósito de lixo" (FRANCISCO, 2015, p. 19). O Papa Francisco assim se pronuncia contra a cultura do descarte, que contrasta negativamente com a sustentabilidade exemplar da natureza em seus ecossistemas. É já um consenso científico que o planeta Terra está passando por um alarmante processo de aquecimento do sistema climático, e que ele tem como causa a atividade humana. Um tema complexo e que envolve tudo aquilo que foi até então discutido, a condição atual do nosso planeta é tratada com urgência por ambas as agendas. É objeto dos ODS 13, 14 e 15 o combate às mudanças climáticas, a destruição, conservação e uso sustentável dos oceanos e ecossistemas. A Agenda 2030, assim, propõe uma série de metas que idealizam desde a minimização dos impactos antrópicos, à conservação dos ecossistemas por meio de novos mecanismos de gestão, tecnologia e cooperação internacional, evidenciando, sobretudo, a importância da educação ambiental. O caminho para o desenvolvimento sustentável necessariamente passa pela relação social com o meio ambiente da qual é parte. As duas agendas convergem ao evidenciarem a importância do desenvolvimento de políticas eficientes quanto à redução da emissão de gases do efeito estufa, por meio da substituição dos combustíveis fosseis e do desenvolvimento de fontes de energia limpa. 
O tema da energia é abordado pelo ODS 7, trazendo o compromisso com a garantia do acesso universal e sustentável à energia, sobretudo, por meio da cooperação internacional, pela qual se pretende aumentar a participação de energias renováveis. A abordagem é semelhante à do Papa. A encíclica Laudato Si, porém, assume uma postura dura quanto a diversos aspectos do atual cenário. O Papa faz crítica intensa à ineficiência das agendas precedentes em corresponder às expectativas e à realização das metas ambientais às quais se comprometeram. Segundo Francisco, a falta de rigidez e decisão política, e de mecanismos de controle e revisão resultaram em uma ausência de progresso. Ao abordar potenciais soluções para essa problemática, o Papa destaca a importância da diversidade, "nenhum ramo das ciências e nenhuma forma de sabedoria pode ser transcurada, nem sequer a sabedoria religiosa com a sua linguagem própria" (FRANCISCO, 2015, p. 50). Nesse mesmo caminho, a encíclica enfatiza a diferença de responsabilidades entre os países, e torna requisito "a honestidade, coragem e responsabilidade, sobretudo dos países mais poderosos e mais poluentes" (FRANCISCO, 2015, p. 131). Por fim, o documento converge com a Agenda 2030 ao enaltecer o potencial da educação ambiental na promoção de mudanças. Francisco aponta para uma positiva sensibilidade ecológica entre os jovens, que se contrasta com uma devastadora cultura de consumo e bem-estar, sendo esse um grande desafio educacional. Ou seja, nessa visão, o enfrentamento da crise atual requer, no âmbito do indivíduo, uma mudança estrutural de seus hábitos, e as instituições sociais têm papel fundamental, como expresso no trecho a seguir.

Compete à política e às várias associações um esforço de formação das consciências da população. Naturalmente compete também à Igreja. Todas as comunidades cristãs têm um papel importante a desempenhar nesta educação. (FRANCISCO, 2015, p. 163)

\subsection{Percentual de concordância temática entre as agendas}

Aanálise das abordagens utilizadas pelas agendas mundiais resulta na afirmação de que, a respeito das principais temáticas analisadas, existem singularidades entre ambas, que se apresentam em todos os 20 temas. No entanto, ao se levar em conta as diferenças de posicionamento político e moral que os documentos possuem perante a sociedade, pode-se apurar a existência de uma concordância em relação à integralidade dos temas tratados. Como afirmado, as singularidades estão presentes e foram apresentadas. Porém, consideradas as essências lógicas que fundamentam as agendas, ao serem confrontadas, ambas apresentam um âmago ideológico muito semelhante. A encíclica Laudato Si é um documento originário de uma instituição religiosa, e traz em seu corpo grande influência dos valores morais que ela carrega. No entanto, como demonstrado, o documento assume uma postura que preza pela interdisciplinaridade na identificação e busca por solução para os problemas do mundo. E isso a aproxima muito da Agenda 2030. O documento da ONU se diferencia em sua forma, sendo mais pragmático ao propor uma sistemática de metas organizadas por objetivos, os 17 ODS. Porém, mesmo se distanciando ao ser muitas vezes mais precisa e menos crítica e espiritual, a Agenda 2030 mostrou ter uma essência lógica que afasta possíveis discordâncias e elucida o poder complementar que a relação entre as duas agendas possui.

\section{CONCLUSÕES}

O presente estudo baseou-se na análise comparativa entre duas das principais 
agendas mundiais. Teve como objetivo identificar as contribuições singulares e as relações que as agendas socioeconômica e ambiental da Organização das Nações Unidas (ONU) e da Carta Encíclica Laudato Si do Vaticano têm que se complementam na realização dos objetivos que propõem. Os resultados obtidos revelaram importantes singularidades entre as abordagens das agendas. O confronto proporcionado pela pesquisa foi capaz de elucidar uma postura mais crítica de Francisco em sua encíclica. Indo a fundo na origem de problemas estruturais, foi demonstrada maior liberdade, por parte do pontífice, em apontar para os erros e falhas das instituições de poder político, econômico e social. Também se mostrou evidente uma postura que dá maior ênfase à importância do individual, do espiritual, realizando uma constante integração do mesmo com o coletivo local e internacional. Já o documento da ONU tem suas singularidades baseadas, sobretudo, em seu pragmatismo. Os 17 ODS se estruturam em sistemática de metas organizadas por objetivos, o que expressa, por muitas vezes, a priorização da objetividade e precisão na proposição de caminhos e soluções para os problemas, em detrimento da exploração da dimensão subjetiva.

As agendas demonstraram, no entanto, uma forte congruência temática, de identificação dos problemas globais, dando ênfases variadas, mas convergindo na proposição de soluções interdisciplinares. Ao longo dos documentos foi constantemente enaltecida a importância da cooperação internacional, educação ambiental e instituições sociais para futura efetivação do que foi então proposto. Integração, transformação, desenvolvimento e universalização, sendo então estabelecida a existência de não duas, mas uma crise socioambiental, que será solucionadaapenas por meio de mudanças de nível estrutural dos hábitos e costumes individuais e sistêmicos, conforme se observa no texto a seguir.

Sem uma mudança de atitude que se concentre no bem-estar do planeta e seus habitantes, os esforços para alcançar as metas de desenvolvimento sustentável da ONU não serão "suficientes para uma ordem mundial justa e sustentável", disse o Papa, no dia 8 de março. (IHU, 2019)

Por fim, conclui-se que as agendas são complementares. Na medida em que os 17 Objetivos de Desenvolvimento Sustentável objetivam a promoção de mudanças externas para a construção de um mundo melhor para as próximas gerações, a agenda do Vaticano releva a necessidade conjunta da promoção de mudanças internas ao indivíduo que, em sua ressignificação de hábitos e pensamentos, permita um novo conceito de felicidade que atinja e preencha os corações e sentimentos.

\section{REFERÊNCIAS}

FRANCISCO, Papa. Carta Encíclica Laudato Si (Sobre o cuidado da casa comum). Cidade do Vaticano, 2015. Disponível em:

https://www.vatican.va/content/dam/francesco/pdf/encyclicals/documents/papafrancesco 20150524 enciclica-laudato-si po.pdf. Acesso em: 30/03/2021.

GIRAUD, G.; ORLIANGE, P. Laudato Si' e os Objetivos de Desenvolvimento Sustentável: uma convergência? Tradução de Vanise Dresch. São Leopoldo: Cadernos Teologia Pública, 2016. 


\section{OBJETIVOS DO DESENVOLVIMENTO SUSTENTÁVEL E LAUDATO SI NA AGENDA SÓcIOECONÔMICA E AMBIENTAL DA ATUALIDADE}

IHU - Instituto Humanitas Unisinos. Papa: o mundo precisa de uma 'conversão ecológica' para promover a sustentabilidade. Revista IHU online. Disponível em: http://www.ihu.unisinos.br/78-noticias/587388-papa-o-mundo-precisa-de-umaconversao-ecologica-para-promover-a-sustentabilidade. Acesso em: 21/11/2019.

KASSAI, J. R.; CARVALHO, N. C.; KASSAI, J. R. S. Contabilidade Ambiental Relato Integrado e Sustentabilidade. São Paulo: GEN Atlas, 2019.

\section{ONU. Transformando nosso mundo: A agenda 2030 para o desenvolvimento sustentável. Nova York, 2015.}

\section{SOBRE OS AUTORES:}
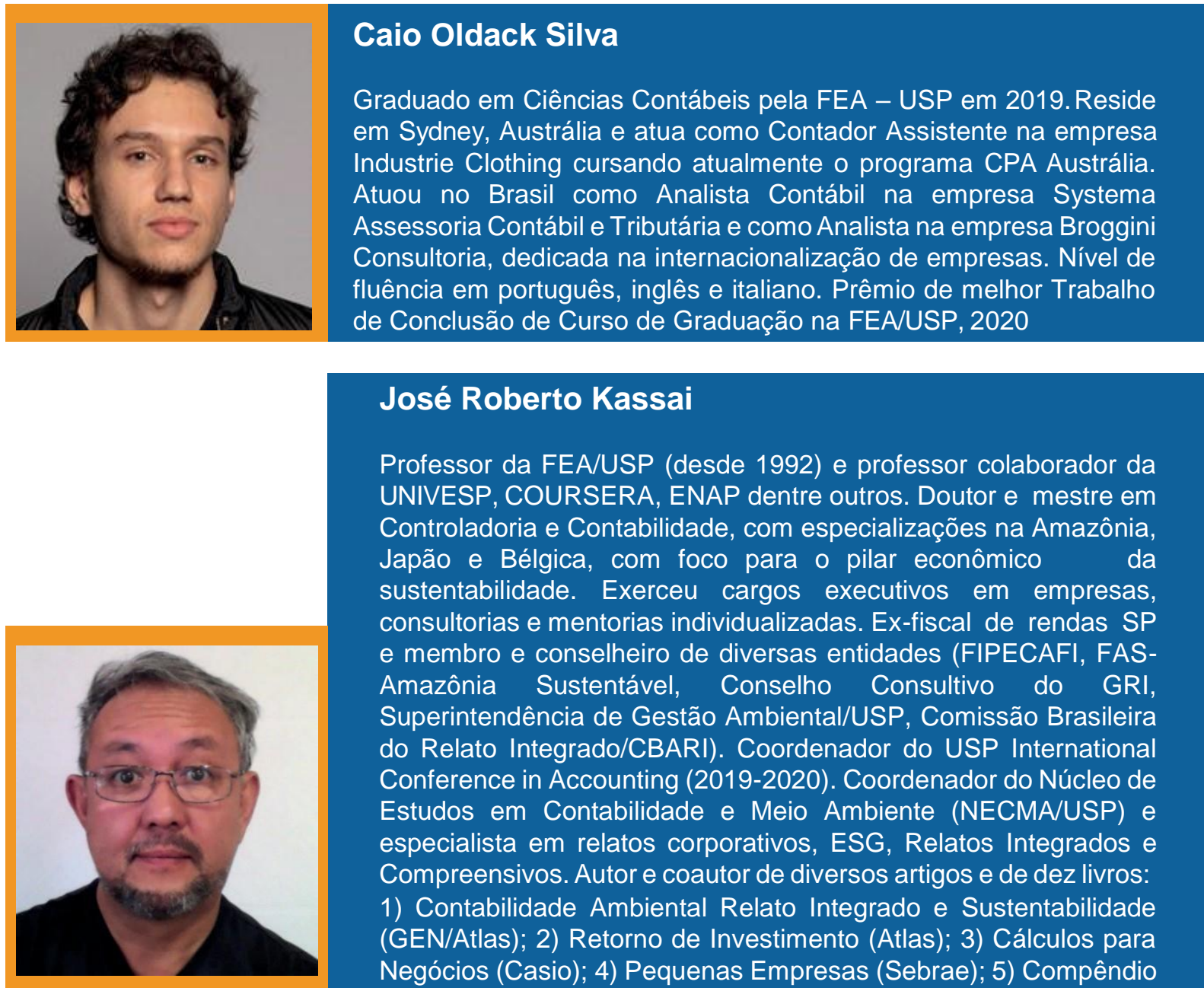

\section{José Roberto Kassai}

Professor da FEA/USP (desde 1992) e professor colaborador da UNIVESP, COURSERA, ENAP dentre outros. Doutor e mestre em Controladoria e Contabilidade, com especializações na Amazônia, Japão e Bélgica, com foco para o pilar econômico da sustentabilidade. Exerceu cargos executivos em empresas, consultorias e mentorias individualizadas. Ex-fiscal de rendas SP e membro e conselheiro de diversas entidades (FIPECAFI, FASAmazônia Sustentável, Conselho Consultivo do GRI, Superintendência de Gestão Ambiental/USP, Comissão Brasileira do Relato Integrado/CBARI). Coordenador do USP International Conference in Accounting (2019-2020). Coordenador do Núcleo de Estudos em Contabilidade e Meio Ambiente (NECMA/USP) e especialista em relatos corporativos, ESG, Relatos Integrados e Compreensivos. Autor e coautor de diversos artigos e de dez livros: 1) Contabilidade Ambiental Relato Integrado e Sustentabilidade (GEN/Atlas); 2) Retorno de Investimento (Atlas); 3) Cálculos para Negócios (Casio); 4) Pequenas Empresas (Sebrae); 5) Compêndio de Indicadores de Sustentabilidade das Nações (WHH); 6) Environmental Equity of Nations - Reflection on the Scenario of Climate Change (McGraw-Hill Italy); 7) Contabilidade Gerencial e Sustentabilidade (Atlas); 8) Relato Integrado - O Futuro da Governança Corporativa IBGC (Saint Paul); 9) Integrated Reporting a new accounting disclosore (Palgrave Macmillan UK - Italy); e 10) Reserva Extrativista Chico Mendes a Socieconomia 25 anos depois (OMNIS SCIENTIA, 2021). 